Research Article

\title{
Neuroprotective Effect of Alkylresorcinols from Wheat Bran in HT22 Cells: Correlation with in vitro Antioxidant Activity
}

\author{
Yanyu Zou, Fengjiao Fan, Yong Fang*, Peng Li, Ji Xia, Xinchun Shen, Qin Liu, Qiuhui Hu \\ College of Food Science and Engineering, Nanjing University of Finance and Economics/Key Laboratory of Grains and Oils Quality Control and \\ Processing/Collaborative Innovation Center for Modern Grain Circulation and Safety, Nanjing 210023, China
}

\section{ARTICLE INFO}

Article History

Received 06 November 2020

Accepted 24 January 2021

Keywords

Wheat bran

alkylresorcinols

neuroprotective effect

antioxidation

\section{ABSTRACT}

Alkylresorcinols (ARs), which are phenolic lipids found in wheat bran, have attracted a considerable amount of attention because of their antioxidant properties. However, the mechanism of ARs for regulating neuroprotective activity remains unclear. The correlation between the cellular neuroprotective effects of ARs in HT22 cells and their in vitro antioxidant activity were investigated. The results showed that two main constituents of crude ARs were C19:0 and C21:0, which was identified by highperformance liquid chromatography-atmospheric pressure chemical ionization tandem mass spectrometry. Pre-treatment with $400 \mu \mathrm{g} / \mathrm{mL}$ crude ARs could protect from $\mathrm{H}_{2} \mathrm{O}_{2}$-induced cellular damage involving low cell viability, leakage of lactate dehydrogenase and decreased superoxide dismutase activity. The maximum radical scavenging ability of DPPH $\bullet$, ABTS $\bullet+, \mathrm{O}_{2}^{-}$ and $\bullet \mathrm{OH}^{-}$was $85.45 \%, 88.89 \%, 84.42 \%$ and $87.36 \%$. The neuroprotection effect of ARs was significantly correlated with in vitro antioxidant capacity, confirmed by the maximum correlation coefficients being $0.9988,-0.9974$ and 0.9972 . The antioxidation of ARs potentially promoted neuroprotective effect and further study is needed to clarify the other mechanism behind ARs benefits.

\section{GRAPHICAL ABSTRACT}
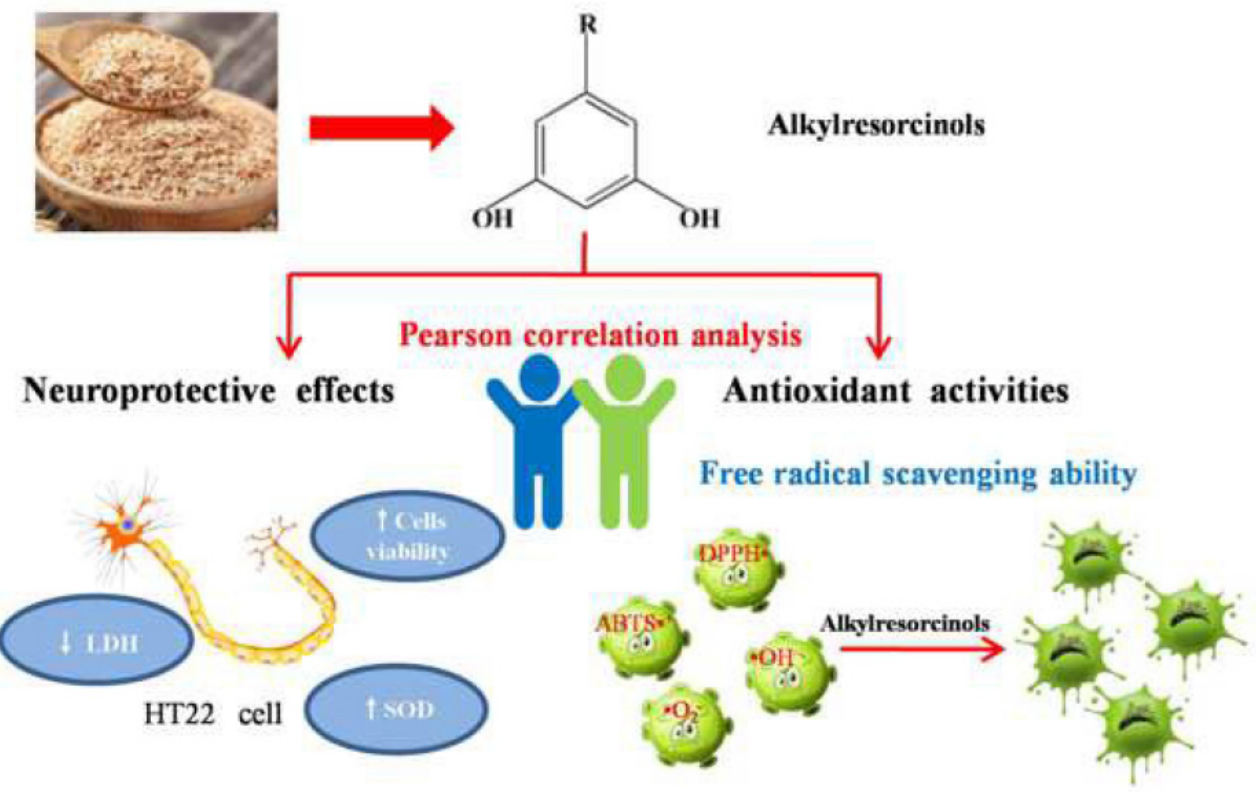

(C) 2021 The Authors. Publishing services by Atlantis Press International B.V. This is an open access article distributed under the CC BY-NC 4.0 license (http://creativecommons.org/licenses/by-nc/4.0/).

"Corresponding author. Email: fangyong10@nufe.edu.cn 


\section{INTRODUCTION}

Alkylresorcinols (ARs) are one of the major phenolic compounds in whole grain cereals; they account for $0.015-0.3 \%$ of the grains dry weight [1]. ARs are special phenolic lipids in the outer layers of wheat and rye grains and other cereal grains [2] and have been considered biomarkers of whole cereals grains intake [3-5]. The homologs of ARs were distinguished by their alkyl side chain, which vary from 17 to 25 carbon atoms [6]. In previous research, High-performance Liquid Chromatography Mass Spectrometry (HPLC-MS) was extensively performed to measure and identify individual ARs homologs in cereals products. Evidence showed that the majority of homologs was saturated; only $0.5-20 \%$ unsaturated and oxygenated homologs were detected in cereals [7]. The chain length and structure of AR homologs have significant impacts on their bioactivity [8].

Polyphenols and phenolic compounds are bioactivity nutrients that generally originate from fruits, vegetables and cereals [9]. In recent years, numerous experimental researches demonstrated that polyphenols and phenolic compounds were beneficial for neurodegenerative diseases [10,11]. The neuroprotective activity of phenols may be closely related to their antioxidant activity. For example, epigallocatechin-3-gallate, the main polyphenol constituent in green tea, could be used as neuroprotective agents because of its radical scavenging capacity, iron-chelating property and antioxidant enzymes regulation ability [12]. Shi et al. [13] discovered that isoliquiritigenin could deduce reactive oxygen species (ROS) production to prevent cell apoptosis and exhibit cellular neuroprotective and antioxidant activity in $\mathrm{H}_{2} \mathrm{O}_{2}$-treated $\mathrm{PC} 12$ cells. ARs are potential natural antioxidants, which have a similar straight aliphatic hydrocarbon side chain and single phenolic ring with tocopherols. Moreover, ARs could prevent lipid peroxidation in natural membranes, which effectively protected the erythrocyte membrane from $\mathrm{H}_{2} \mathrm{O}_{2}$-induced oxidation [14]. Numerous studies indicated that ARs have many bioactivities, which could reduce blood cholesterol and prevent muscle atrophy and oxidative damage [15-17]. However, relevant studies on the neuroprotective effect of ARs are limited.

Oxidative stress has been regarded as the main pathological factor in the initiation and development of neurodegenerative diseases [18]. Oxidative stress may induce membrane damage in neural cells and accelerate the development of neurodegenerative disorders [19]. Evidence indicated some relationships between neuroprotective effects and antioxidant activity. Phenolic compounds were able to protect neurons against oxidative damage owing to their antioxidant properties [20]. Lu et al. [21] discovered that gallic acid could cross through the liposome membrane to react with the free radical and exhibited neuroprotective effect. ARs have been regarded as antioxidant phenolic lipids, which were effective antioxidants in phospholipid bilayers and could prevent membrane lipid peroxidation. Therefore, ARs may have neuroprotective effects because of their antioxidant activity. However, the correlation between neuroprotective effects and antioxidant activity of ARs has never been determined.

Therefore, the objectives of this study were (1) to obtain ARs with ultrasound from wheat bran and identify ARs homologs by HPLC-MS, (2) to explore the neuroprotective effects and antioxidant activity of ARs in vitro, and (3) to evaluate the relationship between the neuroprotective effects of ARs and the antioxidant activity of ARs in vitro by Pearson correlation analysis.

\section{MATERIALS AND METHODS}

\subsection{Materials and Reagent}

Wheat bran was collected from the Lingshan grain depot (Jiangsu, China). The moisture of all wheat bran was less than $14 \%$. Wheat bran was milled to flour, passed through an 80-mesh sieve, and then stored at $-20^{\circ} \mathrm{C}$ until analysis. Dulbecco's Minimal Essential Medium (DMEM), Fetal Bovine Serum (FBS), penicillin and streptomycin, Methylthiazolyl Tetrazolium (MTT), Dimethyl Sulfoxide (DMSO) and $\mathrm{H}_{2} \mathrm{O}_{2}$ solution $(30 \%$, w/w) were purchased from Sloarbio Technologies (Beijing, China). Lactate Dehydrogenase (LDH), Superoxide Dismutase (SOD) and Bicinchoninic Acid (BCA) were purchased from the Beyotime Biotechnology Institute (Nanjing, China).

\subsection{Preparation of Crude ARs from Wheat Bran}

Wheat bran ARs was obtained by method described in previous studies with some modifications [22]. Crude ARs were extracted by ethyl acetate coupled with an ultrasonic treatment. The mixture was centrifuged and the supernatant fraction was collected and filtered. Ethyl acetate was removed in vacuo at $45^{\circ} \mathrm{C}$ to obtain crude ARs extracts. The main composition of crude ARs extracts were determined by HPLC-Atmospheric Pressure Chemical Ionization Tandem Mass Spectrometry (HPLC-APCI-MS/MS).

\subsection{Main Components Analysis of Crude ARs by HPLC-APCI-MS/MS}

Alkylresorcinols was identified according to a previously reported method with some modification [23]. The quantitative analysis of ARs was analyzed by ZORBAX Stable Bond-C18 column $(150 \times$ $4.6 \mathrm{~mm}^{2}, 5 \mu \mathrm{m}$, Agilent Technologies, California, USA) via HPLC at $35^{\circ} \mathrm{C}$. The column was eluted with mobile phase A $[0.1 \%(\mathrm{v} / \mathrm{v})$ formic acid in methanol] and mobile phase B [0.1\% (v/v) formic acid in water] at a flow rate of $0.5 \mathrm{~mL} / \mathrm{min}$ with $20 \mu \mathrm{L}$ injections. ARs were monitored with a UV detector at $280 \mathrm{~nm}$. The elution procedure started with $85 \%$ of eluent B and increased to $90 \%$ of eluent B from 0 to $5 \mathrm{~min}$, gradually increased to $95 \%$ of eluent B in $10 \mathrm{~min}$, then increased to $100 \%$ in $15 \mathrm{~min}$, and remained at $100 \%$ of eluent B from 15 to $35 \mathrm{~min}$. The recording and evaluation of the chromatograms were performed with Agilent Chem station software (version C.01.03, Agilent Technologies).

The MS qualitative analyses of ARs were performed by mass spectrometer equipped with an APCI source and Agilent Chem Station software. APCI/MS conditions were optimized as follows: positive ion mode; drying gas $\left(\mathrm{N}_{2}\right), 9 \mathrm{~mL} / \mathrm{min}$; nebulizer pressure 60 pis; drying gas temperature, $350^{\circ} \mathrm{C}$; capillary voltage $3500 \mathrm{~V}$; and positive-ion mass range $(\mathrm{m} / \mathrm{z}) 100-800$. 


\subsection{HT22 Cellular Activity Experiment}

\subsubsection{Cell culture}

The mouse hippocampal neuronal cell line (HT22 cells) was obtained from the Institute of Biochemistry and Cell Biology (CAS, Shanghai, China). HT22 cells were cultured in DMEM, including $10 \% \mathrm{FBS}$ and $1 \%$ streptomycin/penicillin, and incubated in a $37^{\circ} \mathrm{C}$ cell culture incubator with $5 \% \mathrm{CO}_{2}$. HT22 cells were seeded in well plates. After $24 \mathrm{~h}$, the medium was discarded and incubated with $100 \mu \mathrm{L}$ fresh DMEM that contains various concentrations $(0,50$, $100,200,400$ and $800 \mu \mathrm{g} / \mathrm{mL})$ of ARs for $24 \mathrm{~h}$. Trolox $(50 \mu \mathrm{mol} / \mathrm{L})$ was treated as the positive group. Then, the cells were treated with $\mathrm{H}_{2} \mathrm{O}_{2}(200 \mu \mathrm{mol} / \mathrm{L})$ for $2 \mathrm{~h}$ to induce oxidative damage.

\subsubsection{Cell cytotoxicity activity, cell viability and morphology}

HT22 cells were seeded in 96-well plates and each well contains $1 \times 10^{4}$ cells. The MTT assay was utilized to evaluate the cytotoxicity and cell viability of HT22 cells. MTT solution $(20 \mu \mathrm{L}, 5 \mathrm{mg} / \mathrm{mL})$ were added to each well for $4 \mathrm{~h}$. Subsequently, $100 \mu \mathrm{L}$ DMSO was added to plates for $30 \mathrm{~min}$ at $37^{\circ} \mathrm{C}$. After blue formazan crystal completely solubilized, the absorbance at $570 \mathrm{~nm}$ was measured by using a microplate reader (Spectra MAX 190, Molecular Devices Inc., CA, USA). The cell viability of the untreated cells group was considered as $100 \%$. To observe the morphological changes, the morphology of HT22 cells were captured using inverted phase contrast microscopy.

\subsection{3. $L D H$ and $S O D$ assay}

HT22 cells $\left(1 \times 10^{4}\right.$ cells) were seeded in 96-well plates and cell supernatants was applied to evaluate the leakage of cytoplasmic LDH enzyme. LDH leakage was measured according to the manufacturer's instructions. $1 \times 10^{5}$ cells $/ \mathrm{mL}$ were seeded in a 6 -well plate and the intracellular SOD levels of HT22 cells were detected by an SOD and BCA kit. The intracellular SOD activity and protein concentrations were determined according to the manufacturer's instructions. The absorbance of LDH and SOD was determined by a microplate reader at 490 and $450 \mathrm{~nm}$.

\subsection{Assay of Antioxidant Activity of ARs in vitro}

\subsection{1. $D P P H \bullet$ radical scavenging ability}

The DPPH• free radical scavenging activity of ARs were determined according to the reported method with slight modifications [24]. ARs were homogeneously dispersed with analytical grade methanol to prepare different concentrations samples $(0.125-2.0$ $\mathrm{mg} / \mathrm{mL})$. In addition, $50 \mu \mathrm{L}$ samples and $200 \mu \mathrm{L} \mathrm{DPPH}$ solution $(0.4 \mathrm{mmol} / \mathrm{L})$ were added and mixed. After the mixture incubated for $30 \mathrm{~min}$ in the dark at room temperature, the absorbance was measured at $517 \mathrm{~nm}$ by a microplate reader. Trolox was used as the positive control. The DPPH scavenging ability was calculated by the following equation:

$$
\begin{aligned}
& \mathrm{DPPH} \bullet \text { free radicals scavenging } \\
& \qquad \operatorname{activity}(\%)=\left[1-\frac{\left(A_{1}-A_{2}\right)}{A_{0}}\right] \times 100
\end{aligned}
$$

where $A_{0}$ is the absorbance of the control (methanol instead of sample solutions), $A_{1}$ is the absorbance of the sample solutions, and $A_{2}$ is the absorbance of the sample conditions as $A_{1}$ with methanol instead of the DPPH solution.

\subsubsection{ABTS॰+ radical scavenging ability}

The ABTS ${ }^{+}$radical scavenging activity assay described by Liu et al. [25] was utilized with some modifications. The $7 \mathrm{mmol} / \mathrm{L}$ ABTS stock water solution was mixed with $2.45 \mathrm{mmol} / \mathrm{L} \mathrm{K}_{2} \mathrm{~S}_{2} \mathrm{O}_{8}$ and placed in the dark at room temperature for $12 \mathrm{~h}$ to generate ABTS $\bullet^{+}$. The solution was diluted with PBS buffer solution $(0.2$ $\mathrm{mol} / \mathrm{L}, \mathrm{pH} 7.4$ ) and measured at $734 \mathrm{~nm}$ by a microplate reader until the absorbance decreased to approximately 0.7 to obtain a working solution. After $20 \mu \mathrm{L}$ sample $(0.125-2.0 \mathrm{mg} / \mathrm{mL})$ was mixed with $200 \mu \mathrm{L}$ working solution, the absorbance was measured at $734 \mathrm{~nm}$. Trolox was used as the positive control. The ABTS• ${ }^{+}$ scavenging ability was calculated by the following equation:

$$
\begin{aligned}
& \mathrm{ABTS} \bullet+\text { radical scavenging } \\
& \text { ability }(\%)=\left[1-\frac{\left(A_{1}-A_{2}\right)}{A_{0}}\right] \times 100
\end{aligned}
$$

where $A_{0}$ is the absorbance of the control (water instead of sample solutions), $A_{1}$ is the absorbance of the sample solutions, and $A_{2}$ is the absorbance of the sample conditions as $A_{1}$ with PBS instead of ABTS.

\subsection{3. $\cdot \mathrm{O}_{2}^{-}$radicals scavenging activity}

$\cdot \mathrm{O}_{2}^{-}$radical scavenging activity of the samples were evaluated according to the method described by Ye et al. [26] with minor modifications. In $3 \mathrm{~mL}$ PBS ( $0.1 \mathrm{~mol} / \mathrm{L}, \mathrm{pH} 7.4), 78 \mu \mathrm{mol} / \mathrm{L} \beta$-nicotinamide adenine dinucleotide, $50 \mu \mathrm{mol} / \mathrm{L}$ Nitroblue Tetrazolium (NBT), and $10 \mu \mathrm{mol} / \mathrm{L}$ phenazine methosulfate were diluted. A series of concentrations of sample solutions $(0.125-2.0 \mathrm{mg} / \mathrm{mL})$ were added and incubated at $25^{\circ} \mathrm{C}$ for $5 \mathrm{~min}$. Trolox was used as the positive control. The absorption was measured at $560 \mathrm{~nm}$. The $\cdot \mathrm{O}_{2}^{-}$radicals scavenging activity was calculated by the following equation:

$$
\begin{aligned}
& \bullet \mathrm{O}_{2}^{-} \text {radicals scavenging } \\
& \qquad \operatorname{activity}(\%)=\left[1-\frac{\left(A_{1}-A_{2}\right)}{A_{0}}\right] \times 100
\end{aligned}
$$

where $A_{0}$ is the absorbance of the control (methanol instead of sample solutions), $A_{1}$ is the absorbance of the samples, and $A_{2}$ is the absorbance of the sample solutions in identical conditions as $A_{1}$ with PBS instead of NBT solution. 


\subsection{4. $\bullet \mathrm{OH}^{-}$radicals scavenging activity}

The $\cdot \mathrm{OH}^{-}$radical scavenging activity was determined according to the reported method [27]. The reaction mixture contained 0.2 $\mathrm{mL}$ ferrosin $(0.75 \mathrm{mmol} / \mathrm{L}), 0.3 \mathrm{~mL}$ phosphate buffer $(0.15 \mathrm{~mol} / \mathrm{L}$, $\mathrm{pH} 7.4), 0.2 \mathrm{~mL} \mathrm{FeSO}(0.75 \mathrm{mmol} / \mathrm{L})$ and $0.2 \mathrm{~mL}$ sample solutions $(0.125-2.0 \mathrm{mg} / \mathrm{mL})$. To terminate the reactions, $0.2 \mathrm{~mL} \mathrm{H}_{2} \mathrm{O}_{2}$ $\left(0.01 \%\right.$, w/v) was added. After incubation at $37^{\circ} \mathrm{C}$ for $60 \mathrm{~min}$, the absorbance was measured at $536 \mathrm{~nm}$. Trolox was utilized as the positive control. The $\bullet \mathrm{OH}^{-}$scavenging activity was calculated by the following equation:

$\bullet \mathrm{OH}^{-}$radical scavenging activity $(\%)=\left[\left(A_{2}-A_{0}\right)-\left(A_{1}-A_{0}\right)\right] \times 100$

where $A_{0}$ is the absorbance of the control (methanol instead of sample solutions), $A_{1}$ is the absorbance of the deionized water instead of $\mathrm{H}_{2} \mathrm{O}_{2}$ and the sample solutions, and $A_{2}$ is the absorbance of the samples.

\subsection{Statistical Analysis}

Data was expressed as the mean \pm Standard Deviation (SD) in triplicates. Origin 8.5 (Origin Lab, USA) was selected for the statistical and graphical analysis. A correlation analysis was performed using the Pearson correlation coefficient. SPSS 22.0 (IBM Corp., Armonk, NY, USA) was conducted to determine the variations between and within experimental groups; the statistical significance was set to $p<0.05$ or $p<0.01$.

\section{RESULTS AND DISCUSSION}

\subsection{Main Structural Composition of Crude ARs}

In our study, the highest extractive rate could be $89.27 \%$ when crude ARs were isolated and extracted by ultrasound-assisted ethyl acetate extraction. As shown in Figure 1A, many peaks were observed in crude ARs. Peak 1 and 2 were selected for the subsequent analysis. Peak 1 and 2 were characterized as C19:0 and C21:0 by MS spectra analysis (Figure $1 \mathrm{~B}$ and $1 \mathrm{C}$ ), which is consistent with previous literature $[28,29]$. The same $\mathrm{MS}^{2}$ product ion was found in both Peak 1 and 2 at $m / z$ 123.4. Apart from $m / z 123.4, m / z 111.4$ and $m / z$ 141.5 was another $\mathrm{MS}^{2}$ product ion in Peak 1 and 2, respectively.

\subsection{Evaluation of Cytotoxicity Activity and Cell Viability of ARs in $\mathrm{H}_{2} \mathrm{O}_{2}$-Induced HT22 Cells}

As shown in Figure 2A, ARs had different effects on cellular viability when the concentrations ranged from 50 to $800 \mu \mathrm{g} / \mathrm{mL}$. When the concentration increased to $800 \mu \mathrm{g} / \mathrm{mL}$, the cellular viability significantly decreased, which indicates that ARs generated cytotoxicity to HT22 cells. Therefore, the concentrations ranged from 50 to $400 \mu \mathrm{g} / \mathrm{mL}$ were chosen for subsequent experiments.

In this experiment, Trolox $(50 \mu \mathrm{mol} / \mathrm{L})$ was used as a positive control due to its antioxidative effects [30]. After treatment with
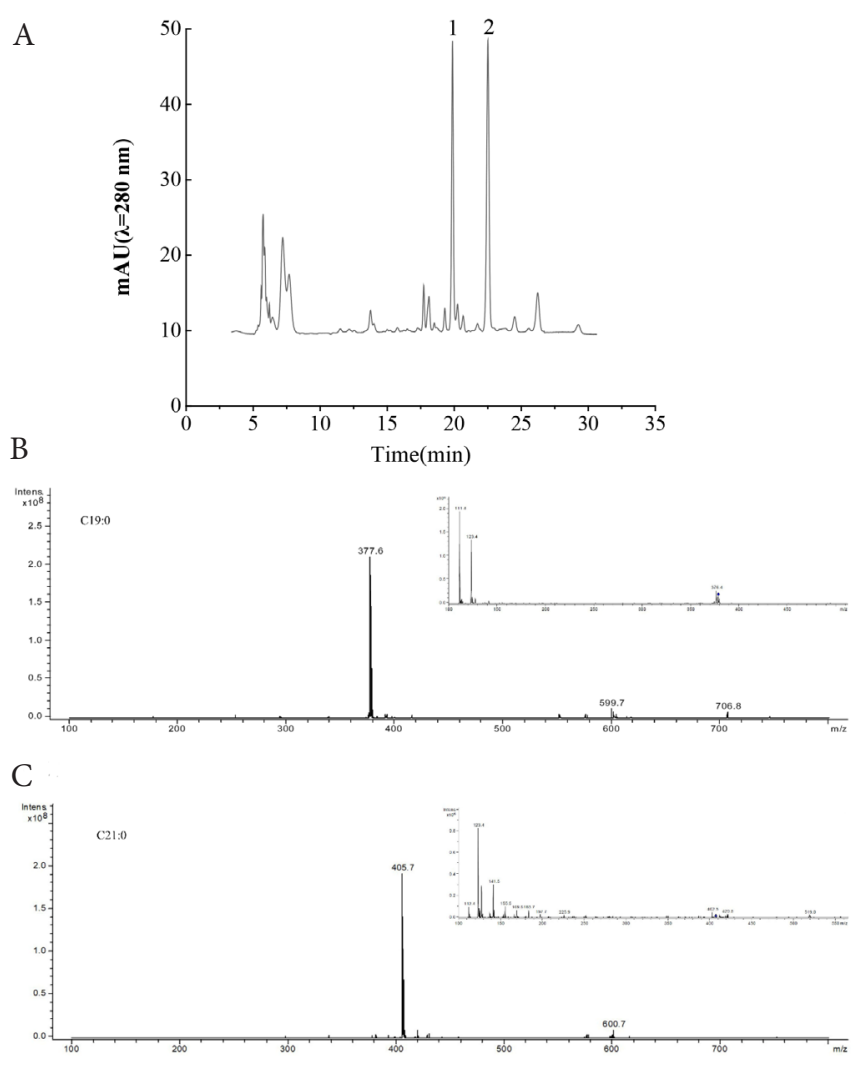

Figure 1 Chromatogram of wheat bran crude ARs. (A), HPLC chromatogram; (B) and (C), ion chromatograms analysis of two main ARs homologs compounds by HPLC-APCI-MS. Peak 1 and 2 (A) are two main ARs homologs and correspond to (B) and (C), respectively.

$\mathrm{H}_{2} \mathrm{O}_{2}(200 \mu \mathrm{mol} / \mathrm{L})$ for $2 \mathrm{~h}$, the cell viability of $\mathrm{HT} 22$ cells significantly decreased to $47.28 \%$ (Figure $2 \mathrm{~B}$ ). However, the cell viability increased from $53.56 \%$ to $84.35 \%$ in the cells experiment groups with a dose-dependent manner. Among all the concentrations, $400 \mu \mathrm{g} / \mathrm{mL}$ ARs showed the most significant effect to improve cell viability. The results indicated that ARs have significant protective effects for alleviating the $\mathrm{H}_{2} \mathrm{O}_{2}$-induced oxidative injury in HT22 cells.

\subsection{Effect of ARs on LDH Release and Intracellular SOD Activity in $\mathrm{H}_{2} \mathrm{O}_{2}$ - Induced HT22 Cells}

As shown in Figure $3 \mathrm{~A}$, the percentage of $\mathrm{LDH}$ release degree remarkably increased to $176.15 \%$ when cells were treated with $\mathrm{H}_{2} \mathrm{O}_{2} . \mathrm{H}_{2} \mathrm{O}_{2}$ can induce oxidative stress, which cause LDH leakage into the culture medium and break down the integrity of cell membranes [31]. All these values clearly implied that ARs could decrease the $\mathrm{LDH}$ release degree. $400 \mu \mathrm{g} / \mathrm{mL}$ ARs reduced the percentage of LDH leakage to $119.78 \%$. Therefore, ARs effectively attenuated the levels of extracellular LDH and avoid the cell membrane fracture induced by $\mathrm{H}_{2} \mathrm{O}_{2}$.

The effect of ARs on the intracellular SOD activity in $\mathrm{H}_{2} \mathrm{O}_{2}$-induced HT22 cells is shown in Figure 3B. The results showed that the intracellular SOD activity was markedly lower after exposure to $\mathrm{H}_{2} \mathrm{O}_{2}$. 

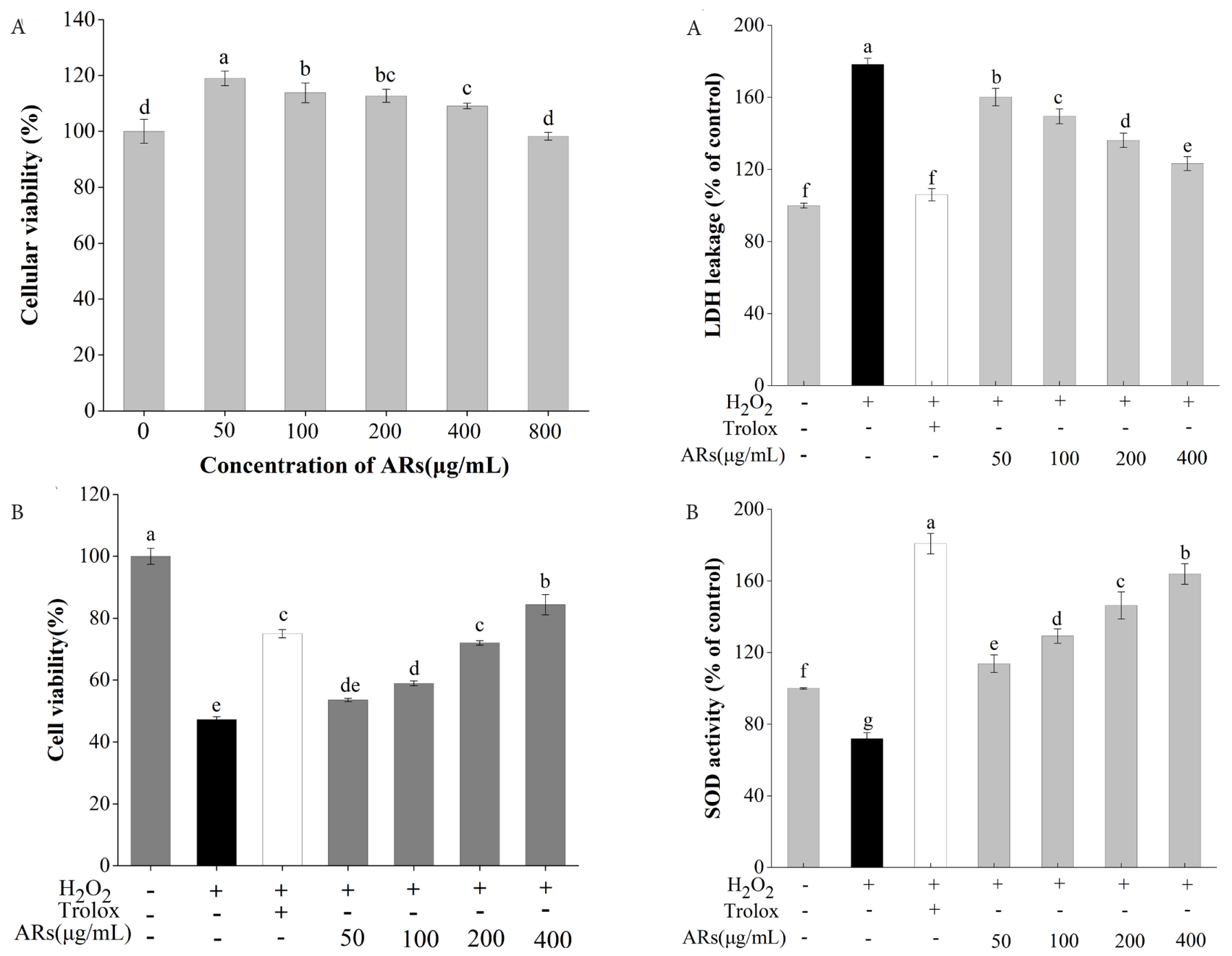

Figure 2 Effects of crude ARs on HT22 cell viability. (A) Determination of ARs dose; (B) Protective effect of ARs in $\mathrm{H}_{2} \mathrm{O}_{2}$-damaged HT22 cells. Results marked with different letters represent significant differences $(p<0.05)$.

However, ARs could increase the intracellular SOD activity in a dose-dependent manner compared with the control group. When the concentration of ARs increased to $200 \mu \mathrm{g} / \mathrm{mL}$, a significant effect on enhancing the intracellular SOD activity was observed. SOD is a pivotal intracellular antioxidant enzyme that could prevent oxidative stress induced by $\mathrm{H}_{2} \mathrm{O}_{2}$ and has an essential role in defense mechanisms against cell-death [24]. Thus, the results showed that ARs could alleviate $\mathrm{H}_{2} \mathrm{O}_{2}$-caused oxidative damage by improving the activity of SOD enzyme.

\subsection{Antioxidant Activity of ARs in vitro}

The antioxidant activities of ARs are shown in Figure 4. With an increase in the AR concentration, the in vitro antioxidant activity enhanced. The DPPH radical scavenging ability of ARs were 10.62$85.45 \%$, respectively. The maximum ABTS $\bullet^{+}, \bullet \mathrm{O}_{2}^{-}$and $\bullet \mathrm{OH}^{-}$radical scavenging ability was $88.89 \%, 84.42 \%$ and $87.36 \%$ at $2 \mathrm{mg} / \mathrm{mL}$ ARs. Among these antioxidant indexes, ARs displayed higher ABTS• ${ }^{+}$ and $\bullet \mathrm{OH}^{-}$radical scavenging function when the concentration is

Figure 3 Effect of ARs on intracellular LDH leakage rate (A) and SOD activity (B) in $\mathrm{H}_{2} \mathrm{O}_{2}$-induced HT22 cells. Results marked with different letters represent significant differences $(p<0.05)$.

the same. These results showed that ARs exhibited significant antioxidant properties.

\subsection{Correlation Analysis between Cellular Neuroprotection and in vitro Antioxidant Activity}

As shown in Figure 4, with an increase in the AR concentration, its antioxidant activity enhanced in vitro. Table 1 showed the coefficient among various parameters, the $\mathrm{LDH}$ release rate had a negative correlation with in vitro antioxidant activity. The value of the coefficient between $\bullet \mathrm{O}_{2}^{-}$scavenging activity and $\mathrm{LDH}$ was -0.9974 $(p<0.01)$. At the same time, the cell viability and SOD had a significant positive correlation with antioxidant activity in vitro. The coefficient value between SOD activity and $\mathrm{DPPH} \bullet$ radicals scavenging activity was $0.9972(p<0.01)$.

The ABTS $\bullet^{+}$radical scavenging activity showed significant correlation to cell viability and correlated extremely significantly with 


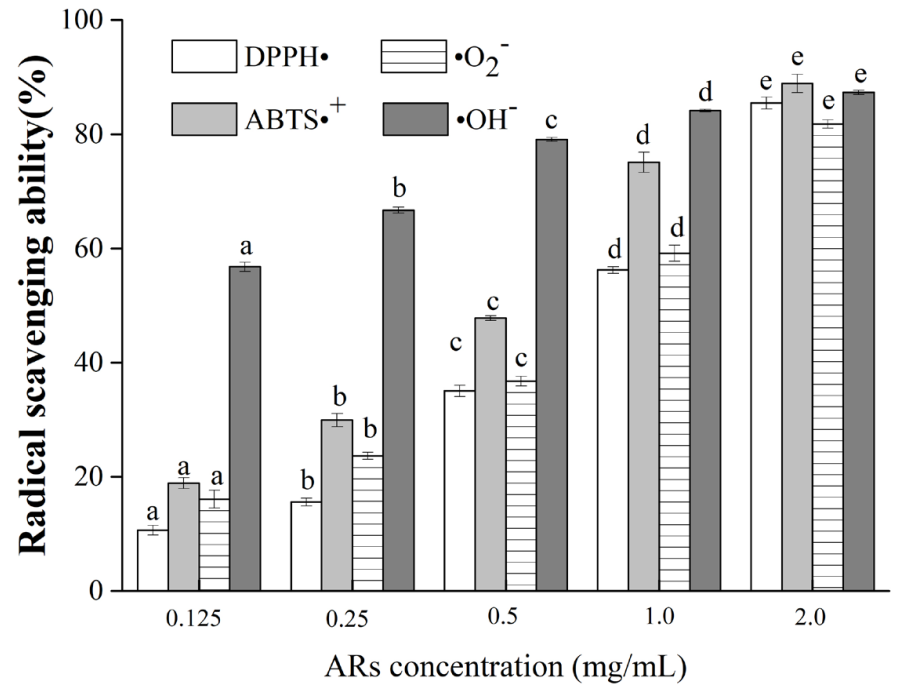

Figure $4 \mathrm{DPPH} \bullet, \mathrm{ABTS}^{+}, \bullet_{2}^{-}$and $\bullet \mathrm{OH}^{-}$radical scavenging capacity of ARs.

Table 1 Correlation coefficient between cellular neuroprotective effect and in vitro antioxidant activity of ARs in HT22 cell

\begin{tabular}{lccc}
\hline & Cell viability & LDH & SOD \\
\hline DPPH• & $0.9955^{* *}$ & $-0.9971^{* *}$ & $0.9972^{* *}$ \\
ABTS $\bullet^{*}$ & $0.9776^{*}$ & $-0.9927^{* *}$ & $0.9918^{* *}$ \\
$\mathrm{OO}_{2}^{-}$ & $0.9988^{* *}$ & $-0.9974^{* *}$ & $0.9960^{* *}$ \\
$\boldsymbol{O O H}^{-}$ & 0.8909 & -0.9384 & 0.9439 \\
\hline
\end{tabular}

*Indicates significant differences at $p<0.05$ and "indicates very significant differences at $p<0.01$ by Pearson correlation analysis.

LDH release rate and intracellular SOD level, marked with correlation coefficients $0.9776,-0.9927$ and 0.9918 . The DPPH• and $\cdot \mathrm{O}_{2}^{-}$radical scavenging was very significantly correlated with three cellular level parameters. The coefficient value between cell viability and $\bullet \mathrm{O}_{2}^{-}$radical scavenging activity was $0.9988(p<0.01)$. The results showed that ARs exhibited neuroprotective effects against oxidative damage via decreasing cellular LDH level, enhancing SOD enzyme activity and free radicals scavenging activity. These results were consistent with the study about Brazilian green propolis. Nakajima et al. [32] reported that Brazilian green propolis has significant antioxidant action toward superoxide anion radicals and NO radicals and its neuroprotective effect was closely related to its antioxidant effect. Moreover, Lu et al. [33] reported that the polyphenols of apple leaves could attenuate the intracellular $\mathrm{LDH}$, regulate the activity of SOD, prevent $\mathrm{H}_{2} \mathrm{O}_{2}$ induced oxidative stress and rat hippocampal neurons death because of its antioxidant properties. Therefore, the mechanisms underlying neuroprotective effects may be related to the antioxidant activities of ARs.

Alkylresorcinols homologs are amphiphilic phenolic lipids that are detected in wheat, rye and other wheat [34]. Hydrophobicity is a particularly important factor in evaluating the intracellular antioxidant capacity [21]. Hydrophobic antioxidants are generally more effective for preventing oxidative stress-induced neurodegenerative diseases. On the other hand, lipophilic polyphenols have a better membrane-penetrating capacity, which may facilitate they enter into neuron cells. Moreover, the human brain has a large content of lipids, where lipophilic antioxidants may represent a higher neuroprotective effect on the oxidative stress [35]. Therefore, the special amphiphilic characteristic account for neuroprotective effects of ARs.

Additionally, the aliphatic side chains of ARs participated in their antioxidant properties [36]. After HT22 cells were exposed to $\mathrm{H}_{2} \mathrm{O}_{2}$, the membrane became severely damaged and generated a large content of reactive oxygen species. The alkyl tail of ARs would interact with phospholipids or proteins to regulate the phospholipid bilayer properties and physicochemicals of the membrane and then modulate the activities of some antioxidant enzymes [37]. After ARs crossed the cell membrane and entered the HT22 cells, they would react with the cellular reactive oxygen species and other free radicals. With the formation of hydroxyl radicals, the electron density of the antioxidant system would change, which cause oxidation of the ARs ring to protect HT22 cells from oxidative damages. Thus, the cellular neuroprotective activity of ARs may depend on its antioxidant activity. Korycińska et al. showed that the difference in the alkyl chain length within AR homologs has a slight impact on their antioxidant properties. In this study, we acknowledged that C19:0 and C21:0 were the predominant ARs homologs in wheat bran. Therefore, the findings concluded that the cellular neuroprotective activity had a positive correlation with the in vitro antioxidant activity. ARs can be used as neuroprotective agents and future research is warranted.

\section{CONCLUSION}

Wheat bran ARs possess not only antioxidant properties but also neuroprotective activity. The neuroprotective activity of ARs in HT22 cells was correlated with its antioxidant activity in vitro. C19:0 and C21:0 are two major ARs homologs in wheat bran and could be the key factors that relate to the $\bullet \mathrm{O}_{2}^{-}$scavenging capacity. However, the molecular mechanism between ARs and oxidative induced damage has not been clarified. Therefore, future studies will focus on the separation and purification of each AR homologue and the relationship between ARs and their neuroprotective effects in vivo, and clarify the specific signaling pathway between the neuroprotective effects and the antioxidant activities of ARs.

\section{CONFLICTS OF INTEREST}

The authors declare they have no conflicts of interest.

\section{AUTHORS' CONTRIBUTION}

YZ carried out the experiments and interpreted the results. FF did some data analysis work. YF designed the study and interpreted the results. PL, JX, XS, QL and QH instructed the instrument operation.

\section{ACKNOWLEDGMENTS}

This work was supported by the National Key Research and Development Program of China (2016YFD0401203), Priority Academic Program Development of Jiangsu Higher Education Institutions (PAPD), and National Youth Talent in Grain Area Support Program of China (LQ2018301). 


\section{REFERENCES}

[1] Ross AB, Kamal-Eldin A, Aman P. Dietary alkylresorcinols: absorption, bioactivities, and possible use as biomarkers of whole-grain wheat- and rye-rich foods. Nutr Rev 2004;62:81-95.

[2] Ross AB, Svelander C, Karlsson G, Savolainen OI. Identification and quantification of even and odd chained 5-n alkylresorcinols, branched chain-alkylresorcinols and methylalkylresorcinols in Quinoa (Chenopodium Quinoa). Food Chem 2017;220:344-51.

[3] Ross AB, Shepherd MJ, Schüpphaus M, Sinclair V, Alfaro B, Kamal-Eldin A, et al. Alkylresorcinols in cereals and cereal products. J Agric Food Chem 2003;51:4111-18.

[4] Ross AB, Aman P, Kamal-Eldin A. Identification of cereal alkylresorcinol metabolites in human urine-potential biomarkers of wholegrain wheat and rye intake. J Chromatogr B Analyt Technol Biomed Life Sci 2004;809:125-30.

[5] Giambanelli E, Ferioli F, D’Antuono FL. Alkylresorcinols and fatty acids in primitive wheat populations of Italian and black sea region countries origin. J Food Compos Anal 2018;69:62-70.

[6] Wierzbicka R, Wu H, Franek M, Kamal-Eldin A, Landberg R. Determination of alkylresorcinols and their metabolites in biological samples by gas chromatography-mass spectrometry. J Chromatogr B Analyt Technol Biomed Life Sci 2015;1000:120-9.

[7] Landberg R, Andersson AAM, Åman P, Kamal-Eldin A. Comparison of GC and colorimetry for the determination of alkylresorcinol homologues in cereal grains and products. Food Chem 2009;113:1363-9.

[8] Liu J, Hao Y, Wang Z, Ni F, Wang Y, Gong L, et al. Identification, quantification, and anti-inflammatory activity of 5-nalkylresorcinols from 21 different wheat varieties. J Agric Food Chem 2018;66:9241-7.

[9] Costa C, Tsatsakis A, Mamoulakis C, Teodoro M, Briguglio G, Caruso E, et al. Current evidence on the effect of dietary polyphenols intake on chronic diseases. Food Chem Toxicol 2017;110:286-99.

[10] Cha SJ, Do HA, Choi HJ, Lee M, Kim K. The Drosophila model: exploring novel therapeutic compounds against neurodegenerative diseases. Antioxidants 2019;8:623.

[11] Renaud J, Martinoli MG. Considerations for the use of polyphenols as therapies in neurodegenerative diseases. Int J Mol Sci 2019;20:1883.

[12] Reznichenko L, Amit T, Zheng H, Avramovich-Tirosh Y, Youdim $\mathrm{MBH}$, Weinreb $\mathrm{O}$, et al. Reduction of iron-regulated amyloid precursor protein and $\beta$-amyloid peptide by (-)-epigallocatechin-3gallate in cell cultures: implications for iron chelation in Alzheimer's disease. J Neurochem 2006;97:527-36.

[13] Shi D, Yang J, Jiang Y, Wen L, Wang Z, Yang B. The antioxidant activity and neuroprotective mechanism of isoliquiritigenin. Free Radic Biol Med 2020;152:207-15.

[14] Korycińska M, Czelna K, Jaromin A, Kozubek A. Antioxidant activity of rye bran alkylresorcinols and extracts from wholegrain cereal products. Food Chem 2009;116:1013-18.

[15] Oishi K, Yamamoto S, Itoh N, Nakao R, Yasumoto Y, Tanaka K, et al. Wheat alkylresorcinols suppress high-fat, high-sucrose diet-induced obesity and glucose intolerance by increasing insulin sensitivity and cholesterol excretion in male mice. J Nutr 2015;145:199-206.

[16] Hiramoto S, Yahata N, Saitoh K, Yoshimura T, Wang Y, Taniyama S, et al. Dietary supplementation with alkylresorcinols prevents muscle atrophy through a shift of energy supply. J Nutr Biochem 2018;61:147-54.
[17] Wang Z, Hao Y, Wang Y, Liu J, Yuan X, Sun B, et al. Wheat alkylresorcinols protect human retinal pigment epithelial cells against $\mathrm{H}_{2} \mathrm{O}_{2}$-induced oxidative damage through Akt-dependent $\mathrm{Nrf} 2 /$ HO-1 signaling. Food Funct 2019;10:2797-804.

[18] Cassidy L, Fernandez F, Johnson JB, Naiker M, Owoola AG, Broszczak DA. Oxidative stress in Alzheimer's disease: a review on emergent natural polyphenolic therapeutics. Complement Ther Med 2020;49:102294.

[19] Langasco R, Fancello S, Rassu G, Cossu M, Cavalli R, Galleri G, et al. Increasing protective activity of genistein by loading into transfersomes: a new potential adjuvant in the oxidative stressrelated neurodegenerative diseases? Phytomedicine 2019;52:23-31.

[20] Delgado-Marin L, Sánchez-Borzone M, García DA. Neuroprotective effects of gabaergic phenols correlated with their pharmacological and antioxidant properties. Life Sci 2017;175:11-15.

[21] Lu Z, Nie G, Belton PS, Tang H, Zhao B. Structure-activity relationship analysis of antioxidant ability and neuroprotective effect of gallic acid derivatives. Neurochem Int 2006;48:263-74.

[22] Geng P, Harnly JM, Chen P. Differentiation of whole grain from refined wheat (T. aestivum) flour using lipid profile of wheat bran, germ, and endosperm with UHPLC-HRAM mass spectrometry. J Agric Food Chem 2015;63:6189-211.

[23] Gunenc A, Kong L, Elias RJ, Ziegler GR. Inclusion complex formation between high amylose corn starch and alkylresorcinols from rye bran. Food Chem 2018;259:1-6.

[24] Liu J, Luo J, Ye H, Sun Y, Lu Z, Zeng X. In vitro and in vivo antioxidant activity of exopolysaccharides from endophytic bacterium Paenibacillus polymyxa EJS-3. Carbohydr Polym 2010;82:1278-83.

[25] Liu L, Sun Y, Laura T, Liang X, Ye H, Zeng X. Determination of polyphenolic content and antioxidant activity of kudingcha made from Ilex kudingcha C.J. Tseng. Food Chem 2009;112:35-41.

[26] Ye S, Liu F, Wang J, Wang H, Zhang M. Antioxidant activities of an exopolysaccharide isolated and purified from marine Pseudomonas Pf-6. Carbohydr Polym 2012;87:764-70.

[27] Liu J, Luo J, Ye H, Sun Y, Lu Z, Zeng X. Production characterization and antioxidant activities in vitro of exopolysaccharides from endophytic bacterium Paenibacillus polymyxa EJS-3. Carbohydr Polym 2009;78:275-81.

[28] Bordiga M, Locatelli M, Travaglia F, Arlorio M, Reyneri A, Blandino $\mathrm{M}$, et al. Alkylresorcinol content in whole grains and pearled fractions of wheat and barley. J Cereal Sci 2016;70:38-46.

[29] Giambanelli E, Ferioli F, D’Antuono LF. Retention of alkylresorcinols, antioxidant activity and fatty acids following traditional hulled wheat processing. J Cereal Sci 2018;79:98-105.

[30] Huang S, Meng N, Liu Z, Guo L, Dong L, Li B, et al. Neuroprotective effects of Taraxacum officinale Wigg. extract on glutamateinduced oxidative stress in HT22 cells via HO-1/Nrf2 pathways. Nutrients 2018;10:926.

[31] Ao GZ, Chu XJ, Ji YY, Wang JW. Antioxidant properties and PC12 cell protective effects of a novel curcumin analogue (2E,6E)2,6-bis(3,5-dimethoxybenzylidene)cyclohexanone (MCH). Int J Mol Sci 2014;15:3970-88.

[32] Nakajima Y, Shimazawa M, Mishima S, Hara H. Water extract of propolis and its main constituents, caffeoylquinic acid derivatives, exert neuroprotective effects via antioxidant actions. Life Sci 2007;80:370-7.

[33] Lu Y, Du Y, Qin X, Wu H, Huang Y, Cheng Y, et al. Comprehensive evaluation of effective polyphenols in apple leaves and their combinatory antioxidant and neuroprotective activities. Ind Crops Prod 2019;129:242-52. 
[34] Elder AS, Coupland JN, Elias RJ. Antioxidant activity of a winterized, acetonic rye bran extract containing alkylresorcinols in oil-in-water emulsions. Food Chem 2019;272:174-81.

[35] Chu YF, Brown PH, Lyle BJ, Chen Y, Black RM, Williams CE, et al. Roasted coffees high in lipophilic antioxidants and chlorogenic acid lactones are more neuroprotective than green coffees. J Agric Food Chem 2009;57:9801-8.
[36] Hladyszowski J, Zubik L, Kozubek A. Quantum mechanical and experimental oxidation studies of pentadecylresorcinol, olivetol, orcinol and resorcinol. Free Radic Res 1998;28:359-68.

[37] Gunenc A, HadiNezhad M, Tamburic-Ilincic L, Mayer PM, Hosseinian F. Effects of region and cultivar on alkylresorcinols content and composition in wheat bran and their antioxidant activity. J Cereal Sci 2013;57:405-10. 